\title{
De Nederlandse Staat als aandeelhouder in Air France/KLM: een nieuwe deelneming, een nieuw deelnemingenbeleid
}

Mr. J. Nijland

Met de aankoop van aandelen in Air France-KLM hoopt de Nederlandse Staat de internationale bereikbaarheid van Nederland beter te borgen. Deze bijdrage bespreekt in hoeverre deze aankoop de positie van de Staat versterkt en hoe het huidige deelnemingenbeleid aldus verruimd lijkt te worden met ruimte voor nieuwe overheidsdeelnemingen.

\section{Introductie}

In de afgelopen jaren zijn de verhoudingen tussen moedermaatschappij Air France-KLM S.A. en haar Nederlandse dochter KLM N.V. steeds verder op scherp komen te staan. ${ }^{1}$ Op 26 februari 2019 kondigde minister van Financiën Hoekstra de aankoop van een pakket aandelen in de vennootschap Air France-KLM door de Nederlandse Staat aan. ${ }^{2}$ Deze laatste ontwikkeling in de saga van de onderneming is opmerkelijk omdat deze een mogelijke verruiming van het algemene beleid ten aanzien van de door de Nederlandse Staat te houden deelnemingen illustreert. Het is de vraag in hoeverre de Nederlandse Staat met de aankoop zijn greep op de onderneming effectief heeft versterkt, en of de betrokken Nederlandse publieke belangen zo beter geborgd kunnen worden. Deze vraag wordt beantwoord in samenhang met een bespreking van de mogelijke betekenis van de aandelenaankoop voor het deelnemingenbeleid van de Nederlandse Staat.

Hiertoe zal eerst de governance van Air France-KLM worden toegelicht en de zorgen van de Nederlandse Staat ten aanzien hiervan (par. 2). Daarna wordt de aankoop van de aandelen door de Staat en de nieuwe positie van de Staat als minderheidsaandeelhouder in de holding bekeken. Daarbij wordt ingegaan op de vraag in hoeverre de juridische mogelijkheden voor de Nederlandse Staat om invloed in de holding uit te oefenen hierdoor toenemen (par. 3). De aankoop van de aandelen Air France-KLM en de mogelijke betekenis daarvan voor het Nederlandse deelnemingenbeleid in brede zin worden tezamen met de fases van het Nederlandse deelnemingenbeleid besproken (par. 4). Ik sluit af met enkele concluderende opmerkingen (par. 5).

\section{De governance van Air France-KLM in vogelvlucht}

De oorsprong van de alliantie tussen Air France en KLM ligt in 2003, wanneer de aandeelhoudersvergaderingen van de respectievelijke vennootschappen besluiten dat de luchtvaartmaatschappijen samen verder zouden gaan in een steeds verder consoliderende luchtvaartmarkt. ${ }^{3}$ Bij de overname door Air France - door de minister van Financiën steevast als 'samenwerking' aangeduid - werden afspraken gemaakt ter behartiging van het Nederlandse publieke belang. Het belang voor de Nederlandse samenleving als geheel van de nationale luchtvaartmaatschappij KLM is onlosmakelijk verbonden met de relevantie van thuishaven Schiphol als netwerkhub voor intercontinentale bestemmingen. ${ }^{4}$ Het Nederlandse belang in KLM is dus gelegen in de internationale bereikbaarheid van Nederland. ${ }^{\mathbf{5}}$ Een zekere mate van invloed van de Staat om het behoud daarvan voor de Nederlandse samenleving te garanderen werd bij de overname daarom wenselijk geacht. Deze invloed moest onder meer worden verzekerd door het sluiten van staatsgaranties voor de duur van zeven jaar en een aandelenbelang van de Nederlandse Staat van 5,9\% in dochter KLM van de holding Air France-KLM. ${ }^{6}$ Aanvankelijk leken de 'State assurances' afdoende voor een vruchtbare samenwerking. ${ }^{7}$ Deze garanties zijn na het aflopen ervan in 2010 deels verlengd, maar met de kanttekening dat Air France-KLM deze vanaf dat moment steeds eenzijdig met een opzegtermijn van negen maanden kan beëindigen. ${ }^{\mathbf{8}}$ Ook werd de governance van de onderneming, aldus de minister van Financiën, 'minder evenwichtig' door een vergroting van 'de board van Air France-KLM en de Executive Committee' en zodoende een minder prominente rol voor de vertegenwoordigers van KLM hierin.9 De gewijzigde governance baart de Nederlandse Staat zorgen. De afgelopen jaren is een aantal keren wrijving tussen het beleid van moeder Air France-KLM en dochter KLM en tussen Frankrijk en Nederland als belanghebbenden ontstaan. Illustratief is de wens van de moederonderneming om na een sterke daling van de winst in 2015 de winst van de Nederlandse dochter af te romen en ten goede van de Franse dochter Air France te laten komen. Er werd gevreesd voor een mogelijke parallel in de belangenafwegingen van de onderneming ten aanzien van vliegveld Charles de Gaulle of Schiphol als 'key hubs' ${ }^{10}$ Zorgen over de behartiging van het Nederlandse belang groeiden. Zo stelt de minister van Financiën in de brief waarin de aankoop van de aandelen wordt gemeld aan de Eerste en de Tweede Kamer dat:

'(...) het Nederlandse deel niet voldoende meegenomen is in belangrijke besluiten voor het gehele bedrijf, die ook KLM en de netwerkkwaliteit raken. Zo is het kabinet niet geconsulteerd over de strategische samenwerking met Delta Airlines en China Eastern Airlines. Ook is de Nederlandse staat noch KLM geconsulteerd over een mogelijke overname van het aandelenbelang in Air FranceKLM van de Franse staat door AccorHotels, in het voorjaar van 2018. Mogelijke gevolgen voor het Nederlands publieke belang worden, in de optiek van het kabinet, in de huidige constellatie dus niet voldoende meegewogen. $\mathbf{1 1}$

Met de toetreding van Delta Airlines en China Eastern Airlines werd verwacht dat de strategie en de besluiten over KLM en het Nederlandse publieke belang steeds meer op holdingniveau gecentreerd zouden worden. Ogenschijnlijk de druppel die de emmer deed overlopen, is de discussie die recentelijk ontstond alvorens de Nederlandse CEO van KLM, de heer Elbers, herbenoemd werd. ${ }^{\mathbf{1 2}}$ In de wandelgangen werd gefluisterd dat ondanks de goede resultaten van KLM onder zijn leiding herbenoeming niet zeker was. Kort daarna is besloten dat de Nederlandse Staat een vrijwel vergelijkbaar aandelenbelang in de holding Air FranceKLM als dat van de Franse staat zou moeten verwerven: 'Op deze manier is er invloed en formele zeggenschap op het hoogste niveau (in de Air France-KLM holding), wat een belangrijk sluitstuk is om het publieke belang te borgen', aldus de minister. ${ }^{\mathbf{1 3}} \mathrm{Er}$ zijn echter enkele kanttekeningen te plaatsen. Deze worden tezamen met de regeling in de volgende paragraaf besproken. 


\subsection{Minderheidspositie Nederlandse Staat in vennootschap met een doelstelling met een Franse slag}

Air France-KLM is op grond van haar statuten een Franse société anonyme geregeerd naar geldend Frans recht. ${ }^{\mathbf{1 4}}$ In de doelomschrijving van Air France-KLM worden noch de specifieke Franse, noch de specifieke Nederlandse betrokken publieke belangen expliciet genoemd. ${ }^{\mathbf{1 5}}$ Het aanschaffen van een aandelenbelang in de Air France-KLM-holding verleent de Staat formele zeggenschap in de moedermaatschappij die hij met alleen zijn aandelen in de Nederlandse dochter niet had. Met het verkregen belang van $14 \%^{\mathbf{1 6}}$ is de Staat minderheidsaandeelhouder in Air France-KLM. Als minderheidsaandeelhouder van deze Franse vennootschap heeft de Staat stemrecht in de aandeelhoudersvergaderingen van Air France-KLM. Dit betekent dat de Staat zijn stem ten minste één keer per jaar kan uitbrengen tijdens de jaarlijkse algemene aandeelhoudersvergadering en voorts stemrecht heeft tijdens bijzondere aandeelhoudersvergaderingen. Met 14\% van de aandelen heeft de Staat een behoorlijke stem, maar over het algemeen geschiedt het aannemen of verwerpen van besluiten in beginsel bij gewone meerderheid. Om een dergelijke vereiste meerderheid te verkrijgen, zodat de Staat eventuele onwelgevallige besluiten kan tegenhouden, zal de Staat in de praktijk dus moeten samenwerken met andere aandeelhouders. Indien het verkrijgen van een meerderheidsbelang geprefereerd zou worden boven deze situatie waarin steeds een ad-hocsamenwerking moet worden bewerkstelligd, moet worden vermeld dat dit niet onopgemerkt zal kunnen worden uitgevoerd, aangezien artikel 9.4 jo. artikel 14 van de statuten bepalen dat niet alleen de aandeelhouders, maar ook het publiek wordt ingelicht als (buitenlandse) houders $45 \%$ of meer van de aandelen of stemrechten in de holding hebben verkregen. ${ }^{\mathbf{1 7}}$ Aldus worden de aandeelhouders van Air France-KLM naar hun nationaliteit verdeeld in twee verschillende categorieën, te weten een categorie van Franse aandeelhouders en een categorie van niet-Franse, buitenlandse aandeelhouders. Op grond van artikel 9.2 van de statuten van Air France-KLM moeten aandelenbelangen boven een drempel van $5 \%$ worden geregistreerd. Met een aandelenbelang van $14 \%$ moet de Staat dus registreren. Bovendien is de Staat verplicht om de vennootschap op grond van artikel 13 van de statuten steeds te informeren wanneer hij zijn belang uitbreidt met ten minste $0,5 \% .{ }^{\mathbf{1 8}}$ Door deze meldingsplicht is inzichtelijk door wie welke aandeelpakketten worden gehouden en aldus welke belangen in de holding worden vertegenwoordigd.

\section{2 (Nog) geen gelijke stemrechten door dubbel stemrecht bij loyaliteitsaandelen}

Wat betreft de vertegenwoordiging van belangen is vermeldenswaardig dat de Franse Staat momenteel met een even groot pakket aandelen als de Nederlandse Staat meer stemrechten heeft omdat hij beroep kan doen op een loyaliteitsregeling. Op grond van het Franse vennootschapsrecht heeft een aandeelhouder die zijn aandelen langer dan twee jaar in een vennootschap houdt, recht op een verdubbeling van zijn stemrechten op grond van die aandelen. ${ }^{\mathbf{1 9}}$ De Nederlandse Staat zal als nieuwe aandeelhouder dus pas eind februari 2021 dezelfde (verdubbeling van) stemrechten bezitten als de Franse overheid omdat de Franse overheid haar aandelen al langer dan twee jaar bezit. Desalniettemin kan de Staat ook met een minderheidsbelang in bepaalde situaties een aanzienlijke invloed op de besluitvorming binnen de algemene aandeelhoudersvergadering uitoefenen. Indien besluiten op grond van de wet of de statuten aan een absolute meerderheid of in ieder geval een 87\%-meerderheid zijn onderworpen, zou de Nederlandse Staat die in de statuten of de Franse wet genoemde besluiten kunnen frustreren omdat zijn minderheidsbelang als het ware als een de-factovetorecht fungeert. ${ }^{\mathbf{2 o}}$ Bovendien is het zo dat het Franse vennootschapsrecht evenals het Nederlandse recht $^{\mathbf{2 1}}$ de regel heeft geïncorporeerd dat een minderheidsaandeelhouder met meer dan $5 \%$ van de aandelen in beginsel niet zonder medewerking is uit te kopen door de meerderheidsaandeelhouder. ${ }^{22}$

\subsection{Het recht op informatie voor de individuele aandeelhouder}

Het kunnen uitbrengen van een stem is belangrijk. Een ander belangrijk recht is het recht op informatie voor de aandeelhouder. Relevant in dat opzicht is de inmiddels door de lidstaten geïmplementeerde Europese Richtlijn inzake aandeelhoudersrechten van 11 juli 2007, die geldt voor beursvennootschappen zoals Air France-KLM. Artikel 9 van de richtlijn

'geeft aandeelhouders het recht om tijdens en voorafgaande aan de vergadering vragen te stellen over geagendeerde onderwerpen. De vennootschap moet deze vragen beantwoorden met inachtneming van de goede orde van de vergadering en de bescherming van de vertrouwelijkheid van de zakelijke belangen van de vennootschap. ${ }^{\mathbf{2 3}}$

Het is lastig voor individuele aandeelhouders om buiten de vergadering inlichtingen te verkrijgen. Hun aanspraak heeft niet dezelfde kracht als die van de vergadering van aandeelhouders als zodanig. Wel hebben aandeelhouders in een Franse vennootschap als Air France-KLM een 'Action Directe', op grond waarvan de individuele aandeelhouder direct tegen de bestuurder van de vennootschap een procedure kan aanspannen. ${ }^{\mathbf{2 4}}$

\section{4 (Een aanpassing van) het Nederlandse deelnemingenbeleid}

Het beleid van de Nederlandse Staat ten aanzien van zijn deelnemingen is vastgelegd in verschillende nota's deelnemingenbeleid. Dit beleid liet zich tot de jaren negentig kenmerken door de wens zo veel mogelijk te privatiseren. ${ }^{\mathbf{2 5}}$ Het uitgangspunt was dat de eigendom van bestaande overheidsdeelnemingen zo veel mogelijk privaat zou moeten worden, tenzij de borging van de betrokken publieke belangen anders vereist. Naar aanleiding van het inzicht dat in sommige gevallen overheidsaandeelhouderschap wenselijk was, kwam in 2007 een wijziging van het beleid met de Nota Deelnemingenbeleid 2007. Het uitgangspunt van dit deelnemingenbeleid laat zich omschrijven als een 'publiek, tenzij'-beleid: overheidsaandeelhouderschap was steeds het uitgangspunt, tenzij de borging van publieke belangen dit niet (langer) vereiste. ${ }^{\mathbf{2 6}}$ Niet langer werd het afstoten van staatsdeelnemingen tot uitgangspunt genomen. Het actief beheren van staatsdeelnemingen kwam voorop te staan. ${ }^{27}$

'Uitgangspunt zou veeleer moeten zijn dat de deelnemingen met een duidelijke verwantschap met het publieke domein in beginsel worden behouden. Een beleid van "publiek, tenzij" dus. ${ }^{28}$

Dit motto 'publiek, tenzij' werd in 2013 formeel losgelaten omdat de overheid niet langer vanuit motto's het beleid wenste te voeren, maar een casusspecifiek beleid voorstond. Per geval zou moeten worden beoordeeld of het overheidsaandeelhouderschap nog aangewezen is. Wel blijft het uitgangspunt dus overheidsaandeelhouderschap, dus 'publiek, tenzij ...' De gemeenschappelijke noemer in het deelnemingenbeleid is steeds geweest dat moest worden bezien of voor de bestaande overheidsdeelnemingen nog plaats was. Er werd niet voorzien in het aangaan van nieuwe (permanente) deelnemingen en deze vonden met uitzondering van de door de financiële crisis noodzakelijke tijdelijke deelnemingen in financiële instellingen, zoals ABN AMRO Bank via NLFI, ook niet plaats. De aanschaf van nieuwe aandelen in Air France-KLM lijkt te wijzen op een verruiming van de visie ten aanzien van het deelnemingenbeleid. Er is naast een beoordeling van bestaande overheidsdeelnemingen ook plaats voor het casuïstisch beoordelen van gevallen waarin mogelijk een nieuwe overheidsdeelneming wenselijk is. Het overheidsaandeelhouderschap wordt 
aldus nieuw leven ingeblazen.

\section{Conclusie}

Voorlopig is dit hoofdstuk in de saga afgesloten met een gezamenlijke verklaring van minister Hoekstra en zijn Franse ambtgenoot die eensgezindheid uitstraalt:

'Wopke Hoekstra and Bruno Le Maire share the same priority: strengthening the group Air France-KLM, a key European actor in

European air transport with a global network of destinations from the hubs of Roissy Charles De Gaulle and Amsterdam Schiphol.'29

Met zijn nieuwe deelneming in Air France-KLM heeft de Nederlandse Staat mogelijkheden voor het uitoefenen van invloed in de holding verkregen, waarmee het Nederlandse belang wordt vertegenwoordigd in de Franse holdingmaatschappij. In deze bijdrage zijn wel enkele kanttekeningen geplaatst bij de effectieve invloed die de Staat met zijn minderheidsbelang heeft verkregen. Vast staat dat de betrokken Nederlandse publieke belangen binnen de Franse moedermaatschappij nu een stem hebben. Met de bespreking van de regeling is ook een eventueel nieuw hoofdstuk ingeslagen voor het deelnemingenbeleid van de Nederlandse Staat. Naast een focus op bestaande deelnemingen lijkt nu ook ruimte te zijn om casus te beoordelen waarin een nieuwe deelneming door de Staat wenselijk is.

\section{Noten}

1 Zie de Volkskrant 28 februari 2019, Waarom 'traditionele tegenspelers' Nederland en Frankrijk zo vaak in de clinch liggen.

2 Zie Kamerstukken II 2019/20, 31936, 579 (brief van de minister van Financiën en de minister van Infrastructuur en Waterstaat).

3 Zie Kamerstukken II 2003/04, 29232, 1.

4 Zie Jaarverslag Beheer Staatsdeelnemingen 2010, Kamerstukken II 2011/12, 28165, 131, p. 43.

5 Kamerstukken II 2019/20, 31936, 579 (brief van de minister van Financiën en de minister van Infrastructuur en Waterstaat), p. 1 .

6 Zie Kamerstukken II 2009/10, 29232, 6. Interessant is dat deze ratio voor het aandeelhouderschap van de Staat in KLM niet meer expliciet wordt benoemd als methode om het publieke belang te borgen in het Jaarrapport deelnemingen 2017. Het publieke belang is, zo lezen we, vooral gebonden aan netwerkkwaliteit, markttoegang en luchtvaartpolitiek en wordt geborgd door de Wet luchtvaart, 'State assurances', Luchtvaartovereenkomsten Nederland en derden en Luchtvaartovereenkomsten Europese Unie en derden. Zie Jaarverslag Beheer Staatsdeelnemingen 2017, Kamerstukken II 2016/17, 28165.

7 Kamerstukken II 2009/10, 29232, 6, waar de toenmalige minister van Verkeer en Waterstaat Eurlings nog spreekt over een herbevestiging van 'de uitstekende samenwerking'.

8 Kamerstukken II 2009/10, 29232, 6 en Kamerstukken II 2019/20, 31936, 579 (brief van de minister van Financiën en de minister van Infrastructuur en Waterstaat).

9 Kamerstukken II 2019/20, 31936, 579 (brief van de minister van Financiën en de minister van Infrastructuur en Waterstaat), p. 2.

10 J. Nijland, Troubled times for Air France/KLM, Leiden Law Blog 26 februari 2015, zie https://leidenlawblog.nl/articles/troubled-times-for-air-france-klm.

11 Kamerstukken II 2019/20, 31936, 579 (brief van de minister van Financiën en de minister van Infrastructuur en Waterstaat), p. 3 .

12 Zie de brief, p. 2.

13 Zie de brief, p. 4-5.

14 Zie de statuten van Air France-KLM S.A. geldend per 14 november 2014, te raadplegen via:

www.airfranceklm.com/en/articles-incorporation, overigens met nog een verwijzing naar het in 2010 ingetrokken art. L. 330-1 van de Franse civiele Luchtvaartwet. Voor de nieuwe tekst wordt verwezen naar art. L6412-2 van de Transportwet:

www.legifrance.gouv.fr/affichCodeArticle.do;jsessionid=F86445E4854F3341BCoo6oB92B556707.tplgfr31s_2?

cidTexte=LEGITEXToooo23086525\&idArticle=LEGIARTIooo023077832\&dateTexte=20190305\&categorieLien=id\#LEGIARTIoooo2307783

15 Volgens art. 2 van de statuten valt onder het doel van de vennootschap onder meer het verkrijgen van (in)directe deelnemingen in het kapitaal van vliegmaatschappijen in any manner whatsoever, of the operations pertaining to its corporate purpose'.

16 Aanvankelijk werd een belang van 12,68\% gemeld. Inmiddels heeft de Staat een belang van $14 \%$ verworven en is blijkens een bericht van 27 februari 2019 het kopen van aandelen Air France-KLM gestopt: www.rijksoverheid.nl/ministeries/ministerie-vanfinancien/nieuws/2019/o2/27/update-nederlandse-staat-verwerft-14-procent-aandelen-in-holding-air-france-klm.

17 Zie art. 14 van de statuten, dat overigens ook een definitie geeft van de term French nationals.

18 Het artikel bepaalt: '(...) any private individual or legal entity, whether acting alone or in conjunction with others, who comes to hold, whether directly or indirectly, $0.5 \%$ at least of the share capital or voting rights in the Company, or any multiple of that percentage, shall be bound to inform the Company by letter sent registered or certified mail, return receipt requested, within fifteen days of the date on which this equity threshold has been reached. The declaration for which the preceding paragraph provides shall be repeated on each occasion that a further threshold of $0.5 \%$ of voting rights is reached, up to $50 \%$.' Zie overigens 
de sanctie van art. 13 van de statuten: 'Failure to adhere to the obligation to make the equity threshold declarations required by law and the Articles of Incorporation, shall lead to disqualification of the stock for voting under Article L. 233-14 of the Code of Commercial Law at the request of one or more shareholders holding together at least $0.5 \%$ of the share capital of the Company.'

19 Zie art. L 225-123 Code de Commerce (CdC). Zie A.A. Bootsma, Loyaliteitsstemrecht in het Franse wetsvoorstel-Florange, Ondernemingsrecht 2014/43.

2o Voor bepaalde besluiten zouden de statuten eenstemmigheid kunnen eisen, waardoor de overheid aan slechts één aandeel voldoende heeft om deze besluiten te controleren. In de statuten zal echter uitdrukkelijk moeten zijn opgenomen welke besluiten dit zijn, met als consequentie dat ook andere aandeelhouders belangrijke besluitvorming kunnen frustreren.

21 Op grond van de Wft zijn aandeelhouders sinds 31 december 2008 verplicht een verworven belang in de vennootschap te melden wanneer bepaalde drempelwaarden worden bereikt. Zie art. 5:33 t/m 5:52 Wft en in het bijzonder art. 5:38 lid $3 \mathrm{Wft}$.

22 Zie de uitkoopregeling van art. 2:201a BW. Slechts in uitzonderlijke gevallen zal een minderheidsaandeelhouder zich kunnen verzetten tegen uitkoop. Zie bijv. art. 2:201a lid 4 BW en nader J. Winter, Van Schilfgaarde. Van de BV en de NV, Deventer: Wolters Kluwer 2017, nr. 130.

23 Zie Van Schilfgaarde/Winter 2017/64.

24 In Nederland is daarvoor geen afzonderlijke wettelijke regeling, maar bestaat wel de mogelijkheid om een enquêteprocedure te starten om onderzoek naar het bestuur van een vennootschap te verrichten.

25 Zie Kamerstukken II 2012/13, 28165, 148, p. 7.

26 Zie Kamerstukken II 2007/o8, 28165, 69, p. 18 (Nota Deelnemingenbeleid Rijksoverheid 2007). Er is geen actief afstotingsbeleid en deelnemingen worden niet periodiek doorgelicht op de mogelijkheid om ze al dan niet af te stoten. Zie p. 8 van Jaarverslag Beheer Staatsdeelnemingen 2011 (herziene versie), bijlage bij Kamerstukken II 2012/13, 28165, 145.

27 Zie J. Nijland, De overheidsonderneming. Overheidsinvloed in kapitaalvennootschappen nader beschouwd (Ars Notariatus nr. 154), Deventer: Kluwer 2013, p. 181 e.v.

28 Zie Kamerstukken II 2007/o8, 28165, 69, p. 18 (Nota Deelnemingenbeleid Rijksoverheid 2007): 'Door het veranderde karakter van de huidige portefeuille staatsdeelnemingen is het beleid van "privatiseren, tenzij" naar oordeel van het kabinet toe aan herziening. Een beleid dat privatisering als uitgangspunt heeft, verhoudt zich niet goed met een beleid waarvan het streven is om juist ook het publieke belang binnen de uitoefening van het aandeelhouderschap een duidelijker plaats te geven.'

29 Zie www.government.nl/latest/news/2019/o3/o1/joint-presse-release-on-the-future-of-the-group-air-france-klm. Vermeldenswaardig is dat de Nederlandse Staat, anders dan de Franse Staat, heeft besloten niet in te tekenen op een door Air France-KLM na deze verklaring uitgegeven converteerbare obligatielening, zie FD 20 maart 2019, Staat houdt hand even op de knip bij lening Air France-KLM. 